\title{
The Empirical Study on the Development of Listed Private Enterprises in Hubei Province
}

\author{
Kexin Wang \\ Business School, Manufacturing Industry Development Research Center on Wuhan City Circle, Jianghan University, Wuhan, China \\ Email address: \\ katherinewangkx@hotmail.com

\section{To cite this article:} \\ Kexin Wang. The Empirical Study on the Development of Listed Private Enterprises in Hubei Province. International Journal of Business \\ and Economics Research. Vol. 9, No. 6, 2020, pp. 364-374. doi: 10.11648/j.ijber.20200906.11
}

Received: September 28, 2020; Accepted: October 22, 2020; Published: November 11, 2020

\begin{abstract}
In recent years, with the deepening of economic system reform, private enterprises have become an important force to promote the rapid development of Hubei economy. This article based on the research of 56 Hubei private enterprises listed in A-Share market, finding that the listed private enterprises in Hubei concentrate in developed areas, and most of them are labor-intensive enterprises. The overall scale of these enterprises is growing rapidly, but the profitability needs to be improved. The tax burden is not significantly reduced, and many factors restrict the tax reduction policy; the overall financial situation is poor, and there are large differences among industries. Therefore, enterprises should speed up the upgrading and transformation to improve their market competitiveness. The government should carefully study and formulate incentive and support policies suitable for different enterprises and industries, accelerate the development of listed private enterprises in Hubei Province, and at the same time continue to improve the tax system reform and optimize tax behavior, so as to further reduce the tax burden of private enterprises.
\end{abstract}

Keywords: Hubei, Listed Private Enterprises, Development Ability

\section{Literature Review}

Since the Reform and Opening up Policy, China's private economy has gradually occupied a more and more important position in the development of national economy, so it has been paid increasing attention by scholars.

In the study of its relationship with the state-owned economy, Gongxiang Hong, Qingqing Gu, Meisheng Dong analyzed the panel data of 30 provincial administrative regions in China from 2000 to 2015 based on the theoretical model of symbiotic evolution of two species in biology, which finds that there is an asymmetric and reciprocal symbiotic relationship between the state-owned economy and the private economy in China.[6] Han Yu, Zhonglun Yang, Zengji Song taking Chinese private holding listed companies as samples to studies the political connection effect and mechanism of state-owned shares in private enterprises, which found that state-owned shares can provide more economic resources and development opportunities for the development of private enterprises by relying on the system connection between state-owned shares and the government, so as to improve business performance. [8]
In the study of the development of private economy, Qianling Shen taking the data of Chinese listed private enterprises as the research sample using the cross level model to find that the financial market competition can not only significantly promote the development of private enterprises, but also strengthen the positive effect of corporate governance on the growth of private enterprises and weaken the negative effects. It is a Pareto improvement strategy to promote the growth of private enterprises by improving financial market competition instead of distorted "relationship capital".[12] Jun-Hwan Park, Bangrae Lee, Yeong-Ho Moon, Lee-Nam Kwon based on the data of enterprises from 2010 to 2012 using the basic deductive method to select the suitable fields for the development of small and medium-sized enterprises in Korea, including the data processing methods of KSIC. Through the research of data synthesis processing, finding three sub categories of KSIC suitable for small and medium-sized enterprises: printed circuit board manufacturing industry, engine parts manufacturing industry and vehicle parts manufacturing industry, which indicate that the annual sales value, CR3, $\mathrm{HHI}$ and gagr are the useful factors to find the suitable SMEs. 
[15]

Generally, the existing literature mostly think that private enterprises have become an important force to promote economic development, but there is little comprehensive analysis on the overall data of the current private enterprises, especially the development of Hubei private enterprises or manufacturing industry, which is impossible to accurately analyze and judge the actual development status of individual and industry of private enterprises from the data, or according to the characteristics of different private enterprises and industries to provide corresponding policy suggestions and data support.

This study selects 56 Hubei listed private enterprises listed in A-share market as the research object. Through the comprehensive analysis of the development status, advantages and disadvantages of Hubei listed private enterprises, this paper analyzes the development characteristics, the areas to be encouraged and the bottlenecks of Hubei listed private enterprises and even the whole Hubei private enterprises, so as to provide scientific data support for policies supporting the development of different industries for relevant departments.

\section{Industry Distribution}

According to the guidance on industry classification of listed companies issued by China Securities Regulatory Commission in 2012, the industry classification of listed enterprises in Hubei Province is shown in Table 1.

Table 1. Industry distribution of listed enterprises in Hubei Province.

\begin{tabular}{|c|c|c|c|}
\hline Industry & $\begin{array}{l}\text { Number of Private } \\
\text { Enterprises }\end{array}$ & $\begin{array}{l}\text { Proportion of Listed } \\
\text { Enterprises in the } \\
\text { Industry }\end{array}$ & $\begin{array}{l}\text { Proportion of Listed } \\
\text { Private Enterprises }\end{array}$ \\
\hline Manufacturing & 38 & $59.38 \%$ & $67.86 \%$ \\
\hline Electricity, heat, gas and water production and supply & 1 & $20 \%$ & $1.79 \%$ \\
\hline Construction & 2 & $40 \%$ & $3.57 \%$ \\
\hline Wholesale and Retail & 5 & $50 \%$ & $8.93 \%$ \\
\hline Transportation, Storage and Postal Services & 1 & $33.33 \%$ & $1.79 \%$ \\
\hline Finance & 1 & $33.33 \%$ & $1.79 \%$ \\
\hline Real Estate & 3 & $75 \%$ & $5.36 \%$ \\
\hline Water conservancy, environment and public facilities management & 1 & $50 \%$ & $1.79 \%$ \\
\hline Culture, sports and entertainment & 1 & $33.33 \%$ & $1.79 \%$ \\
\hline Total & 56 & $54.9 \%$ & $100 \%$ \\
\hline
\end{tabular}

More than half of the listed enterprises in Hubei are private enterprises, among which the top three are information transmission, software and information technology service, real estate and manufacturing. In the meantime, half of the industry' private enterprises accounts for more than $50 \%$ of the listed enterprises in the industry, which shows that private enterprises have become the core force in the development of the industry, which plays an important role in the economic development of Hubei. At the same time, the number of listed private enterprises in manufacturing industry is at least 12.7 times that of other industries, which indicates that the development of manufacturing industry is always the key factor directly reflecting the productivity level and economic development of a region.

\section{Geographical Distribution}

The registered places of Hubei listed private enterprises are distributed in 11 administrative regions of the province. The specific situation is shown in table 2 .

Table 2. Regional distribution of listed private enterprises in Hubei Province.

\begin{tabular}{|c|c|c|c|c|c|}
\hline Administrative division & Number of Companies & Proportion & Administrative division & Number of Companies & Proportion \\
\hline Wuhan & 28 & $50 \%$ & Jingzhou & 6 & $10.71 \%$ \\
\hline Xiangyang & 5 & $8.93 \%$ & Huangshi & 4 & $7.14 \%$ \\
\hline Ezhou & 3 & $5.36 \%$ & Qianjiang & 2 & $3.57 \%$ \\
\hline Jingmen & 3 & $5.36 \%$ & YIchang & 2 & $3.57 \%$ \\
\hline Xiantao & 1 & $1.79 \%$ & Xianning & 1 & $1.79 \%$ \\
\hline Suizhou & 1 & $1.79 \%$ & & & \\
\hline
\end{tabular}

Half of Hubei's listed private enterprises are registered in Wuhan, which is far higher than Jingzhou which ranks the second. This shows that although Wuhan, as the "thoroughfare of nine provinces", will bring more pressure on enterprises in terms of rent, manpower and operation costs, after comprehensive consideration of favorable policies, convenient transportation, urban development, population size, the education level and other factors, Hubei listed private enterprises generally believe that the advantages of the provincial capital cities for their survival and development are far greater than the disadvantages.

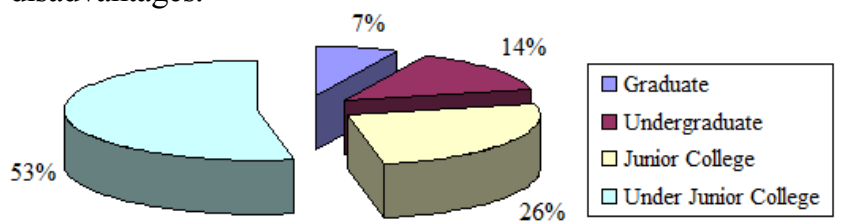

Figure 1. Distribution of Educational Background Structure of Employees in Hubei Listed Private Enterprises. 


\section{Staff Education Structure}

The total number of employees in Hubei listed private enterprises is 176131 , including $65.78 \%$ in manufacturing, $1.41 \%$ in power, heat, gas and water production and supply, $0.44 \%$ in construction, $18.89 \%$ in wholesale and retail, $0.20 \%$ in transportation, storage and postal, $2.59 \%$ in information transmission, software and information technology service, $2.00 \%$ in finance; $7.56 \%$ in real estate; $0.84 \%$ in water conservancy, environment and public facilities management; $0.30 \%$ in culture, sports and entertainment. Compared with the number distribution of the listed private enterprises in Hubei Province, there are great differences in the scale of human resources between the listed private enterprises and among the industries, which indicates that regardless of the individual comparison of enterprises or comparison between industries, the Listed Private Enterprises in Hubei Province have great differences in the development situation.

At present, most of the employees of listed private enterprises in Hubei are below junior college degree, and the number of employees decreases greatly with the increase of educational level. Even the number of employees decreases by nearly half every increase of education level, which indicates that the overall education level of listed private enterprises in Hubei is obviously low.

Table 3. Distribution of Educational Background Structure of Employees by Industry in Hubei Listed Private Enterprises.

\begin{tabular}{lllll}
\hline \multirow{2}{*}{ Industry } & \multicolumn{2}{l}{ Proportion of Employees } & & \\
\cline { 2 - 5 } & $\begin{array}{l}\text { Under Junior } \\
\text { College }\end{array}$ & Junior College & Undergraduate & Graduate \\
\hline Manufacturing & $56 \%$ & $21 \%$ & $19 \%$ & $4 \%$ \\
Electricity, heat, gas and water production and supply & $58 \%$ & $29 \%$ & $12 \%$ & $1 \%$ \\
Construction & $33 \%$ & $28 \%$ & $38 \%$ & $1 \%$ \\
Wholesale and Retail & $45 \%$ & $34 \%$ & $18 \%$ & $3 \%$ \\
Transportation, Storage and Postal Services & $48 \%$ & $25 \%$ & $24 \%$ & $3 \%$ \\
Information Transmission, Software and Information Technology Services & $29 \%$ & $37 \%$ & $32 \%$ & $2 \%$ \\
Finance & $28 \%$ & $23 \%$ & $44 \%$ & $5 \%$ \\
Real Estate & $46 \%$ & $40 \%$ & $13 \%$ & \\
Water conservancy, environment and public facilities management & $70 \%$ & $18 \%$ & $9 \%$ & $1 \%$ \\
Culture, sports and entertainment & $19 \%$ & $13 \%$ & $50 \%$ & $3 \%$ \\
\hline
\end{tabular}

In terms of industries, Hubei listed private cultural, sports and entertainment enterprises have the highest overall education, On the one hand, it shows that compared with other industries, enterprises in this industry pay more attention to employees' knowledge and creativity. On the other hand, it is precisely because of the emphasis on education and knowledge that more high-level talents are willing to work in the industry. This fact may be quite different from the public's understanding of culture, sports and entertainment. In addition to the culture, sports and entertainment industries, enterprises in finance, construction and information transmission, software and information technology service are also more educated than other industries, which indicates that these enterprises have relatively higher ability of technological research and innovation and better treatment, which can attract more high-level talents. While the employees of water conservancy, environment and public facilities management industry have the lowest education level, and the technical content needs to be improved. The production and supply enterprises of power, heat, gas and water and the manufacturing private enterprises are typical labor-intensive enterprises.

\section{Business Income $e^{1}$}

From 2016 to 2018, the total operating revenue of Hubei listed private enterprises was 195447196961.22 yuan, 282468920877.77 yuan and 281636523582.01 yuan respectively, which showed a small decline after a large increase.

Most of the listed private enterprises in Hubei have a total revenue of more than 100 million yuan, and a few enterprises have more than 10 billion yuan. Among them, the number of enterprises with total operating revenue less than 100 million yuan has not changed in three years, accounting for $3.57 \%$ of the total number of listed private enterprises in Hubei Province; the number of enterprises with total operating revenue between 100 million yuan and 1 billion yuan shows a downward trend year by year, accounting for $51.79 \%$, $44.64 \%$ and $35.71 \%$ of the total number of listed private enterprises in Hubei Province, respectively; the number of enterprises with total operating revenue between 1 billion yuan and 10 billion yuan has a gradually rising trend which accounting for $35.71 \%, 37.50 \%$ and $46.43 \%$ respectively, shows that most of the listed private enterprises in Hubei

1Since China Bester Group Telecom CO., LTD. (603220), YOFC (601869), Allmed Medical (002950), Wuhan Easy Diagnosis Biomedicine Co., Ltd. (002932) are all private enterprises listed in 2018 , the number of sample enterprises for operating income and total assets analysis is 56 , and for net profit analysis is 52 . 
have achieved steady growth in operating revenue in three years, while the number of large-scale enterprises with total operating revenue of more than 10 billion yuan presents a stable status after a rapid growth. At the same time, Jointown (600998), an enterprise with the highest total operating revenue in the three years, was 3440.89 times higher than Wcy (600275), the manufacturing enterprise with the lowest total operating income in 2016 and was 5110.74 times in 2017, and in 2018 it was surprisingly 86901.36 times higher than the lowest YANGFANG HOLDING (600421), which indicates that although the overall development scale of Hubei listed private enterprises has gradually expanded from 2016 to 2018, the differences among enterprises have increased significantly.

In terms of industries, the scale of operating revenue of manufacturing industry has increased year by year in recent three years, which has shown a good development trend. The power, heat, gas and water production and supply industries have developed steadily, but the scale of operating revenue is relatively small. In addition to certain fluctuations in large-scale operating income, the wholesale and retail industry has achieved rapid growth in the past three years and has a very good development prospect. The total operating revenue of information transmission, software and information technology service industry increased steadily. The financial industry has formed a mature scale, and its development prospects are particularly good. The scale of the real estate industry, culture, sports and entertainment industry has steadily increased which development prospect is good.

\section{Total Assets}

From 2016 to 2018, the total assets of Hubei listed private enterprises increased with a growth rate of $42.67 \%$, the overall scale has achieved rapid growth, but the difference of total assets among enterprises is rising constantly.

At present, $91.07 \%$ of the listed private enterprises in Hubei have total assets of more than 1 billion, which scale is relatively large. From 2016 to $2018,67.86 \%$ of the total assets increased year by year; $42.86 \%$ had an average annual growth rate of less than $10 \% ; 17.86 \%$ had an average annual growth rate of $10 \%-20 \% ; 39.29 \%$ had an average annual growth rate of more than $20 \%$, indicating that the overall scale development of Hubei listed private enterprises is good.

In terms of industries, $92.11 \%$ of the listed private manufacturing enterprises in Hubei have total assets of more than 1 billion yuan; $65.79 \%$ have increased year by year; $42.11 \%$ have an average annual growth rate of less than $10 \%$, of which $62.5 \%$ have a negative growth; $23.68 \%$ have an average annual growth rate of $10 \%-20 \% ; 34.21 \%$ have an average annual growth rate of more than $20 \%$. The total assets of respect one listed private enterprise in electric power, heat, gas and water production and supply industry and financial industry in Hubei Province exceeded 1 billion yuan, and increased year by year over the past three years which the average annual growth rate was more than $20 \%$, indicating that the total assets scale of the two industries developed very well. In the same way, the total assets of the two listed private construction enterprises in Hubei exceeded 1 billion and increased year by year in three years; however, the average annual growth rate of total assets of one enterprise was between $10 \%$ and $20 \%$, and the other was more than $20 \%$. The total assets of $80 \%$ of the listed private wholesale and retail enterprises in Hubei exceed 1 billion, and $60 \%$ increase year by year; the average annual growth rate of $60 \%$ of the enterprises is less than $10 \%$, of which $33.33 \%$ is less than zero; $40 \%$ have an average annual growth rate of more than $20 \%$, which indicates that there is a big difference in the development of total assets between Hubei listed private wholesale and retail enterprises. The average annual growth rate of the total assets of the listed private transportation, warehousing and postal enterprise in Hubei Province is less than $10 \%$ and didn't increasing yearly, and the total assets are less than 1 billion, indicating that its scale and development potential are insufficient. The total assets of all listed private enterprises in information transmission, software and information technology service industry and real estate industry in Hubei Province exceeded 1 billion yuan; $66.67 \%$ increased year by year; $33.33 \%$ of enterprises in information transmission, software and information technology service industry and $66.67 \%$ in real estate industry had an average annual growth rate of more than $20 \% ; 33.33 \%$ enterprises in real estate and $66.67 \%$ enterprises in information transmission, software and information technology service industry have an annual growth rate of total assets less than $10 \%$, of which half of them have total assets decreased in three years which the difference between enterprises is obvious. The total assets of listed private water conservancy, environment and public facilities management industry and culture, sports and entertainment industry enterprises in Hubei Province have exceeded 1 billion yuan and achieved year by year growth; however, the average annual growth rate of water conservancy, environment and public facilities management enterprises is less than $10 \%$, while that of culture, sports and entertainment enterprises is more than $20 \%$, which shows that the development momentum of culture, sports and entertainment industry is better.

At the same time, through the data analysis, it can be found that the difference of total assets scale among the listed private enterprises at extremal sites within an industry in Hubei Province has no change except for the wholesale and retail enterprises. Specifically, during the three years, the gap of total assets between listed private manufacturing enterprises in Hubei gradually increased, but the speed gradually decreased. The scale of total assets among construction enterprises is approaching rapidly. Although the growth rate of Jointown (600998), which has the largest total assets of wholesale and retail enterprises, has slowed down in the past three years, the gap between it and the enterprises with the smallest total assets in the industry continues to increase. The development prospect of the latter is worrying. The largest total assets of private information transmission, software and information technology service enterprises are surprisingly GOSUN HOLDING (000971), which are 3820594679.5 yuan, 3917779978.06 yuan and 3348614693.79 yuan, respectively, which are higher than Century Network (300494) 2865893630.97 yuan, 2905806559.78 yuan and 2233820503.15 yuan, which are 
the smallest in three years, which on one hand indicates whether the positive correlation between the development status is established remains to be studied, at least the correctness of the listed private information transmission, software and information technology service industry in Hubei needs to be discussed; on the other hand, it also shows that the total assets of listed private information transmission, software and information technology service enterprises in Hubei has not changed much in the past three years. The total assets of Hubei private real estate enterprises changed little in the past three years.

\section{Tax Burden ${ }^{2}$}

From 2016 to 2018 , the average actual tax paid by the listed private enterprises in Hubei accounted for $7.49 \%$, $8.21 \%$ and $7.59 \%$ of operating revenue respectively, and the overall average actual tax burden was $6.51 \%$. This shows that although the government has introduced a number of policies and measures to reduce the tax burden of private enterprises, but from the actual effect, the actual tax burden of listed private enterprises in Hubei Province has not decreased significantly and even showed a certain upward trend.

From 2016 to 2018, the water conservancy, environment and public facilities management industry had the heaviest tax burden, indicating that the government did not support the private capital to enter this industry from the tax perspective. The finance industry has the lightest tax burden, which the actual tax proportion in three years is less than $1 \%$, which shows that the government strongly supports the private capital to enter from the perspective of taxation. However, the continuous rise of the actual tax burden in the three years also indicates that the government support has a downward trend.

The actual tax burden of the construction industry and the culture, sports and entertainment industry continued to decline from 2016 to 2018, which shows that the government obviously supports the development of them through tax policies. The actual tax burden of transportation, warehousing and postal industry continued to rise slightly from 2016 to 2018, indicating that the government's support for private capital to enter the industry has declined from the tax perspective.

Specifically, from 2016 to 2018 , there is a big difference in tax burden among listed private enterprises in Hubei Province, and this gap shows a rising trend of fluctuation. In terms of industry, the actual tax burden of Jumpcan (600566), the heaviest enterprise in Hubei listed private manufacturing industry in 2016, was $19.14 \%$, which was 18.38 percentage points higher than Wcy (600275), the lightest enterprise in the industry. In 2017, the actual tax burden of Steyr Motors (000760), the enterprise with the heaviest tax burden, reached an astonishing $84.54 \%$, which

2Since China Bester Group Telecom CO., LTD. (603220), YOFC (601869), Allmed Medical (002950), Wuhan Easy Diagnosis Biomedicine Co., Ltd. (002932) are all private enterprises listed in 2018, the number of sample enterprises here is 52. was 81.29 times of the actual tax burden of WINGTECH (600745), which has the industry's lightest tax burden. It proves that its poor development is directly related to its heavy tax burden. In 2018, the actual tax burden of YANGFANG HOLDING (600421), the enterprise with the heaviest tax burden, also reached $52.89 \%$, while the actual tax burden of EASTERN GOLD JADE (600086), which was the lightest in the industry, was only $0.40 \%$. Once again, it clearly shows that the degree of tax burden is the key factor affecting the development of enterprises. In 2016, the actual tax burden of Hubei listed private construction enterprises Haibo (300517) was 5.90\%, 1.64 percentage points higher than that of Nusun Landscape (300536), but the total Operating income of that year was lower than that of it 1910112.27 yuan; in 2017, the actual tax burden of Nusun Landscape was $4.14 \%, 1.17$ percentage points higher than that of Haibo, and the total Operating income of that year was higher than that of Haibo 20786005.8 yuan. In 2018, the actual tax burden of Nusun Landscape was $4.28 \%$, which was $2.2 \%$ higher than that of Haibo while the total Operating income of that year was lower than it by 44193075.19 yuan. The repeated data in three years showed that the rationality of tax mechanism needs to be studied. thalys (603716) is the most heavily taxed enterprise in Wholesale and Retail industry in the past three years. Among them, the actual tax burden in 2016 was $10.65 \%$, 9.01 percentage points higher than that of Jointown (600998), which has the lightest industry tax burden in that year. However, its total Operating income was lower than that of Jointown 60929511829.09 yuan. In 2017, its actual tax burden was $8.01 \%$, with a yearly decrease of $2.64 \%$, which was 6.33 percentage points higher than that of HBSXNBM (600293), which was the lightest industry tax burden in that year. Similarly, its total Operating income was lower than that of HBSXNBM by 11129975627.79 yuan. In 2018, its actual tax burden was 9.37\%, 7.58 percentage points higher than that of Jointown, which was the lightest industry tax burden. However, its total Operating income of that year was still lower than that of Jointown 85818912501.67 yuan, indicating that the rationality of Taxation for Hubei listed private wholesale and retail enterprises in the past three years also needs to be discussed. The actual tax burden of Century Network (300494), a listed private information transmission, software and information technology service enterprise in Hubei Province, was $8.04 \%$ in 2016 , $4.72 \%$ higher than that in Gosun Holding (000971), and its operating income was lower than it of 321885302.8 yuan. In 2017, the actual tax burden of $8.4 \%$ of Gosun Holding exceeded that of Century Network, but the gap narrowed to 1.14 percentage points. In 2018, the actual tax burden of Gosun Holding rose by $7.15 \%, 2.78$ percentage points higher than that of Century Network, but the total operating income of the two enterprises both increased year by year. Again, the actual tax effect of Hubei listed private enterprises in Information Transmission, Software and Information Technology Services in the past three years has not reached the original 
intention. HBFX (000926), the most heavily taxed enterprise in Hubei listed private real estate industry, had a real tax burden of $9.69 \%$ in 2016 , which was $2.24 \%$ lower than that of guochuang hi-tech (002377), which has the lightest tax burden in the industry. In 2016, the actual tax burden of Kinghand Industrial Investment Group Co. Ltd (000615), the most heavily taxed enterprise, was $10.29 \%$. However, its total operating income was the lowest, only $23.97 \%$ of F HBFX. In 2018, the situation became more serious, the actual tax burden of Kinghand Industrial Investment Group Co. Ltd reached $17.32 \%$. However, its operating income in that year was only $26.91 \%$ of that of HBFX and $63.18 \%$ of that of guochuang hi-tech. At that time, the actual tax burden of guochuang hi-tech was only $5.54 \%$. The actual tax burden of listed private real estate enterprises in Hubei Province in the past three years also shows that the actual effect of tax burden has a serious deviation.

Table 4. Average Actual Tax Burden of Hubei Listed Private Enterprises by Industry from 2016 to 2018.

\begin{tabular}{|c|c|c|c|}
\hline \multirow{2}{*}{ Industry } & \multicolumn{3}{|c|}{ Taxes Paid/ Operating Revenue } \\
\hline & 2016 & 2017 & 2018 \\
\hline Manufacturing & $7.92 \%$ & $9.41 \%$ & $8.35 \%$ \\
\hline Electricity, heat, gas and water production and supply & $10.00 \%$ & $6.12 \%$ & $6.64 \%$ \\
\hline Construction & $5.08 \%$ & $3.55 \%$ & $3.18 \%$ \\
\hline Wholesale and Retail & $4.70 \%$ & $4.21 \%$ & $5.07 \%$ \\
\hline Transportation, Storage and Postal Services & $3.21 \%$ & $3.53 \%$ & $3.87 \%$ \\
\hline Information Transmission, Software and Information Technology Services & $5.68 \%$ & $7.83 \%$ & $5.76 \%$ \\
\hline Finance & $0.27 \%$ & $0.28 \%$ & $0.71 \%$ \\
\hline Real Estate & $8.92 \%$ & $7.95 \%$ & $11.02 \%$ \\
\hline Water conservancy, environment and public facilities management & $14.67 \%$ & $12.55 \%$ & $12.27 \%$ \\
\hline Culture, sports and entertainment & $12.25 \%$ & $7.64 \%$ & $2.74 \%$ \\
\hline
\end{tabular}

In recent years, the government has continuously introduced various measures to reduce the tax burden of private enterprises. However, it can be seen from the above research that the actual tax burden of listed private enterprises in Hubei Province hasn't been significantly reduced from 2016 to 2018, and even some enterprises and industries show the phenomenon of tax burden rising instead of falling, and many enterprises with excessive tax burden are just enterprises with poor development, which clearly shows the tax revenue Burden has become an important factor restricting the development of listed private enterprises in Hubei Province.

At present, the growth rate of tax payment of private enterprises exceeds that of large enterprises for many years, which has become an important source of national tax revenue. However, there is a big contrast between their financial contribution and tax burden, which may be caused by many factors. For example, tax reduction measures bring about other forms of tax increase, or various kinds of tax recovery and supplementary payment in reality; or although the "business tax to value-added tax" policy aims to reduce the tax burden of private enterprises, but on the one hand enterprises also need to pay other taxes, such as stamp tax; on the other hand, in addition to paying tax, enterprises also need to pay education surcharges, water conservancy construction fees, labor and other extra expenses, as well as various administrative and institutional fees collected by industrial and commercial, environmental protection, health, public security and other departments, and even various temporary fees for handling certificates and training. Before the reform of the Levy of these extra tax fees, it is very difficult for private enterprises to obtain substantial decrease in tax burden

\section{Financial Capacity ${ }^{3}$}

\subsection{Analysis of Solvency}

\subsubsection{Short Term Solvency}

In 2016 and 2017, the current assets of listed private enterprises in Hubei were under utilized, and the overall short-term solvency was better in 2018. In the past three years, the overall short-term solvency of listed private enterprises in Hubei Province has improved year by year, and the overall financial risk of listed private enterprises in Hubei Province has decreased continuously.

In terms of industry, in 2016, Hubei listed private enterprises in transportation, warehousing and postal industry, real estate industry, wholesale and retail industry and construction industry had strong short-term solvency; water conservancy, environment and public facilities management industry were significantly short of short-term solvency, while information transmission, software and information technology service industries were seriously under utilized. In 2017, Hubei listed private enterprises in the construction industry and real estate industry have strong short-term solvency; water conservancy, environment and public facilities management enterprises are seriously lack of short-term solvency, while the information transmission,

3Since China Bester Group Telecom CO., LTD. (603220), YOFC (601869), Allmed Medical (002950), Wuhan Easy Diagnosis Biomedicine Co., Ltd. (002932) are all private enterprises listed in 2018, except the sample number of common stock earnings per share analysis is 56 , the number of other financial index analysis sample is 52 . 
software and information technology service industries are still under utilized. In 2018, the finance and construction enterprises have stronger short-term solvency; the power, heat, gas and water production and supply industries were the most lack of short-term solvency. Although the utilization effect of current assets in information transmission, software and information technology service industry was significantly improved compared with the previous two years, it was still extremely insufficient.

\subsubsection{Long Term Solvency}

From 2016 to 2018, the overall long-term solvency of Hubei listed private enterprises is good, but with the passage of time, the overall long-term solvency decreases year by year.

Table 5. Average asset liability ratio of Hubei listed private enterprises by industry in 2016-2018.

\begin{tabular}{|c|c|c|c|}
\hline \multirow{2}{*}{ Industry } & \multicolumn{3}{|c|}{ Asset Liability Ratio } \\
\hline & 2016 & 2017 & 2018 \\
\hline Manufacturing & $32.48 \%$ & $33.99 \%$ & $36.46 \%$ \\
\hline Construction & $37.60 \%$ & $44.18 \%$ & $50.42 \%$ \\
\hline Wholesale and Retail & $47.73 \%$ & $49.44 \%$ & $48.40 \%$ \\
\hline Transportation, Storage and Postal Services & $49.63 \%$ & $39.12 \%$ & $39.94 \%$ \\
\hline Information Transmission, Software and Information Technology Services & $6.56 \%$ & $5.60 \%$ & $26.69 \%$ \\
\hline Finance & $82.70 \%$ & $80.98 \%$ & $85.41 \%$ \\
\hline Real Estate & $61.78 \%$ & $56.36 \%$ & $57.58 \%$ \\
\hline Water conservancy, environment and public facilities management & $66.47 \%$ & $67.49 \%$ & $65.92 \%$ \\
\hline Culture, sports and entertainment & $31.00 \%$ & $46.43 \%$ & $60.17 \%$ \\
\hline
\end{tabular}

In terms of industry, finance enterprises had the worst long-term solvency in three years, information transmission, software and information technology service enterprises did not make good use of financial leverage in 2016 and 2017, although in 2018 it has improved, it is still unsatisfactory. In 2016, Hubei listed private enterprises in transportation, warehousing and postal industry and wholesale and retail industry had most strong long-term solvency; In 2017, it were listed private enterprises in wholesale and retail industry and culture, sports and entertainment industry; In
2018, enterprises in the construction industry, power, heat, gas and water production and supply industry and wholesale and retail industry have most strong long-term debt paying ability.

\subsection{Analysis of Operation Capability}

The overall average operating cash utilization efficiency of Hubei listed private enterprises from 2016 to 2018 is shown in table 6.

Table 6. Overall average operating cash use efficiency of Hubei listed private enterprises in 2016-2018.

\begin{tabular}{llll}
\hline \multirow{2}{*}{ Financial Index } & Index & & \\
\cline { 2 - 4 } & $\mathbf{2 0 1 6}$ & $\mathbf{2 0 1 7}$ & $\mathbf{2 0 1 8}$ \\
\hline Operating Cash Utilization Efficiency & 1.12 & 1.05 & 1.10 \\
\hline
\end{tabular}

From 2016 to 2018, the overall average operating cash utilization efficiency of Hubei listed private enterprises has always been relatively stable, but from the specific value point of view, although the overall normal circulation of
Hubei listed private enterprises in 2016-2018 is not a big problem, it is obvious that the short-term cash is insufficient and the overall operating capacity of the enterprises is not good.

Table 7. Average operating cash use efficiency of Hubei listed private enterprises by industry from 2016 to 2018.

\begin{tabular}{llc}
\hline \multirow{2}{*}{ Industry } & \multicolumn{2}{c}{ Operating Cash Utilization Efficiency } \\
\cline { 2 - 3 } & $\mathbf{2 0 1 6}$ & $\mathbf{2 0 1 7}$ \\
\hline Manufacturing & 1.15 & 1.06 \\
Electricity, heat, gas and water production and supply & 1.20 & 1.07 \\
Construction & 1.08 & 1.43 \\
Wholesale and Retail & 0.98 & 0.74 \\
Transportation, Storage and Postal Services & 0.98 & 1.01 \\
Information Transmission, Software and Information Technology Services & 1.25 & 1.08 \\
Finance & 0.80 & 1.20 \\
Real Estate & 1.16 & 1.03 \\
Water conservancy, environment and public facilities management & 1.08 & 1.26 \\
Culture, sports and entertainment & 0.64 & 1.01 \\
\end{tabular}


From the perspective of industry, the overall operation capacity of Hubei listed private enterprises in various industries is not very good from 2016 to 2018. Among them, in 2016, Hubei listed private enterprises in information transmission, software and information technology service industry and power, heat, gas and water production and supply industry had relatively good operation capacity; enterprises in culture, sports and entertainment industry, finance industry, wholesale and retail industry, transportation, storage and postal industry lacked enough cash to maintain normal reproduction in a short period of time, even short of cash repayment floating debt. In 2017, the operation capacity of Hubei listed private enterprises in the Electricity, heat, gas and water production industry and supply and Water conservancy, environment and public facilities management industry was relatively good; the construction industry and real estate industry enterprises were relatively lack of operation capacity. The overall operating capacity of Hubei listed private enterprises in 2018 is better than that in 2016 and 2017, among which the water conservancy, environment and public facilities management industry and finance industry are relatively optimal, while those of information transmission, software and information technology service industry and wholesale and retail industry are relatively weak.

\subsection{Analysis of Profitability}

From 2016 to 2018, the overall profitability of listed private enterprises in Hubei Province has declined, and the difference among enterprises is rising and has a trend of rapid growth.

In terms of industries, the profitability of listed private enterprises in Hubei Province in 2016 was the strongest in Electricity, heat, gas and water production and supply industry, while the profitability of water conservancy, environment and public facilities management enterprises was the worst and even negative. In 2017, the profitability of Electricity, heat, gas and water production and supply enterprises remained the strongest while the water conservancy, environment and public facilities management enterprises was still the worst, but improved. In 2018, the listed private enterprises in Hubei Province still have the strongest profitability in Electricity, heat, gas and water production and supply industry, while transportation, storage and postal enterprises have the relatively worst profitability.

Specifically, the differences in profitability among listed private manufacturing enterprises in Hubei province continued to expand over the past three years; the earnings per share of common stock of construction enterprise Haibo in 2016 and 2017 were 0.5 yuan and 0.34 yuan, respectively, exceeding 0.13 yuan and 0.03 yuan of Nusun Landscape, respectively. In 2018, Nusun Landscape surpassed Haibo to reach a common share earnings of 0.31 yuan, with a gap of
0.07 yuan; the enterprises with the highest common stock earnings per share in the wholesale and retail industries in the three years were Jointown, which were 0.54 yuan, 0.87 yuan and 0.73 yuan respectively; and the enterprises with the lowest common stock earnings per share in the three years were HSGC (600774), with the difference of 0.47 yuan, 0.78 yuan and 0.64 yuan respectively, both the performance of enterprises and the gap between enterprises are increasing first and then decreasing. In the past three years, the profits of high-quality enterprises in information transmission, software and information technology service industry continued to improve, while the enterprises with the worst profitability continued to decline, and the difference between the two profitability was expanding. The profitability differences among enterprises in real estate industry were large and expanding. From 2016 to 2018, except for Biocause Pharma (000627) in finance industry, which earnings per share of common stock continued to decline, and profitability continued to decline in three years, other industries which have only one enterprise all experienced the earnings per share of common stock increased continuously, the prospect of profitability is good. Especially for BESTSUN RNREGY (600681) in electricity, heat, gas and water production and supply industry, the earnings per share of common stock continued to rise from 0.63 yuan to 0.98 yuan in the past three years, which has strong profitability and good development prospects. In 2016 and 2017, the top three industries with the biggest difference in profitability are manufacturing, real estate and wholesale and retail. In 2018, the top three industries are manufacturing, Information Transmission, Software and Information Technology Services and real estate.

\subsection{Analysis of Development Ability}

From 2016 to 2018, the overall average net profit growth rate of listed private enterprises in Hubei Province showed a trend of first increasing and then decreasing, and in 2018, compared with 2017 , there was a negative growth, and the overall development ability was reduced. Sante (002159), an enterprise in water conservancy, environment and public facilities management, had the highest profit growth rate in the past three years. In 2017, its net profit growth rate reached an astonishing 21133\%, which was 22639.75 percentage points higher than that of Infotmic Co. Ltd (000670), the manufacturing enterprise with the lowest growth rate of net profit. In 2018, its net profit growth rate dropped sharply to $2736.88 \%$, the gap between it and Gosun Holding in Information Transmission, Software and Information Technology Services, which has the lowest net profit growth rate narrowed to 4237.8 percentage points, indicating that there was a huge difference in the overall net profit growth rate of Hubei listed private enterprises from 2016 to 2018 , but the gap gradually narrowed. 
Table 8. Growth rate of average net profit of Hubei listed private enterprises by industry from 2016 to 2018.

\begin{tabular}{|c|c|c|}
\hline \multirow{2}{*}{ Industry } & \multicolumn{2}{|c|}{ Net Profit Growth Rate } \\
\hline & 2017 & 2018 \\
\hline Manufacturing & $-77.42 \%$ & $-72.13 \%$ \\
\hline Electricity, heat, gas and water production and supply & $56.43 \%$ & $16.71 \%$ \\
\hline Construction & $-8.77 \%$ & $-14.94 \%$ \\
\hline Wholesale and Retail & $103.49 \%$ & $5.34 \%$ \\
\hline Transportation, Storage and Postal Services & $423.04 \%$ & $20.45 \%$ \\
\hline Information Transmission, Software and Information Technology Services & $9.44 \%$ & $-769.35 \%$ \\
\hline Real Estate & $177.63 \%$ & $165.46 \%$ \\
\hline Water conservancy, environment and public facilities management & $21133 \%$ & $2736.88 \%$ \\
\hline Culture, sports and entertainment & $1.15 \%$ & $-45.62 \%$ \\
\hline
\end{tabular}

In terms of industries, compared with 2016, the net profit growth rate of water conservancy, environment and public facilities management enterprises of Hubei listed private enterprises in 2017 was 49.96 times higher than that in transportation, storage and postal industry, which ranked the second in growth rate, indicating that the development ability of water conservancy, environment and public facilities management enterprises in 2017 was significantly improved compared with that in 2016; in three years, water conservancy, environment and public facilities management industry had a significant improvement compared with other industries, the growth rate of net profit of manufacturing, construction and finance enterprises has continued to decline for three consecutive years, and the development ability is poor.

\section{Research Conclusions and Policy Recommendations}

\subsection{Research Conclusions}

\subsubsection{Hubei Listed Private Enterprises Are Concentrated in Developed Areas, and Most of Them Are Labor-intensive Enterprises}

From the previous analysis, it can be seen that from the perspective of industry distribution, the vast majority of listed private enterprises in Hubei are manufacturing enterprises; from the perspective of geographical distribution, half of Hubei listed private enterprises are located in Wuhan, which is more than 4.67 times of Jingzhou, which ranks the second in the number of enterprises. This on one hand shows that Hubei has better policy support for manufacturing private enterprises and has given better support to related enterprises, at the same time, it also shows that the current geographical conditions and economic development structure of Hubei Province, especially Wuhan, are obviously favored by private manufacturing enterprises, and manufacturing industry is still the key factor to support the current development of private economy in Hubei Province. On the other hand, it also shows that the regional economic development really greatly affect the decision-making of private enterprises' location, and the better the regional economic development is, the more attractive it will be to private enterprises. From the perspective of staff education structure, the overall education level of Hubei listed private enterprises is obviously low, and they are still mainly labor-intensive economic industries. Among them, Water conservancy, environment and public facilities management industry, Electricity, heat, gas and water production and supply industry and Manufacturing industry are the most serious, while the enterprises in the culture, sports and entertainment industry, finance industry, construction industry and information transmission, software and information technology service industry are ahead of other industries in transformation and upgrading, and pay more attention to scientific and technological research and development and innovation.

\subsubsection{The Overall Scale of Listed Private Enterprises in Hubei is Growing Rapidly, but the Profitability Needs to Be Improved}

From 2016 to 2018, the total operating income and total assets of listed private enterprises in Hubei Province increased rapidly. Although the overall operating income slowed down in the later period of rapid growth, the overall growth rate was still considerable, indicating that the current listed private enterprises in Hubei have achieved rapid expansion in scale and good development momentum. At the same time, the overall net profit of Hubei listed private enterprises did not grow synchronously from 2016 to 2018 , on the contrary, it showed a downward trend. On the one hand, it may be due to the excessive pursuit of expanding the scale but have not reached scale economy effect due to the limitation of their own conditions while making great efforts to invest capital, the huge investment in the early stage has not been rapidly transformed into the promotion of economic interests of enterprises; on the other hand, it may also be due to the decision-making mistakes of listed private enterprises in Hubei Province, although the scale of enterprises has been expanded but the increased profit can not make up for the cost increase caused by the expansion scale, so the net profit does not rise but decreases.

\subsubsection{The Tax Burden of Listed Private Enterprises in Hubei Province Has Not Been Significantly Reduced, and Many Factors Restrict the Tax Reduction Policy}

From the previous analysis, it can be seen that the overall tax burden of listed private enterprises in Hubei Province has not decreased from 2016 to 2018; in terms of industries, 
except the tax burden of finance industry and transportation, storage and postal industry is relatively low, and the tax burden of culture, sports and entertainment industry has decreased rapidly in the three years, the tax reduction effect of other industries is not good. On one hand, this may be due to the difference in the intensity of tax reduction for different industries; on the other hand, we must also see the hedging tax reduction effect that may be caused by the imperfect tax mechanism in China. For example, after the implementation of the policy of replacing business tax with value-added tax, due to the fact that a large proportion of the cost of some industries can not be deducted, the tax bearing cost in the short term will increase; at the same time, the in price tax borne by enterprises in the past is transformed into non price tax after the "business tax to value-added tax", resulting in adverse selection effect. Another example is that the input income given by the government to private enterprises with preferential policies such as discount interest, technology investment, reward and project support is regarded as the income base for enterprises to pay income tax due to the disharmony of local policies and central tax system, which offsets the preferential policies for the development of private enterprises and reduces the incentive effect of policies; it also weakens the difference of policies and leads to the self payment and self collection of state funds. Or, due to the lack of complete coordination between accounting system and tax system, unclear timing of tax rights and responsibilities and value realization causes intangible assets investment are recorded according to the evaluation value of income present value, and the tax department collects asset value-added tax on spot or by stages directly affects the enthusiasm of intangible assets investment activities; It is a common situation that large and medium-sized enterprises in enterprise production and operation require private small and medium-sized enterprises Invoice first, delay payment, which leads to the problems of tax occupation and non refunding in advance, which directly affects the cash flow of private enterprises; the advance collection of private enterprises is regarded as income to collect tax, which also leads to the problems of delayed tax refund and government debt.

\subsubsection{The Overall Financial Situation of Listed Private Enterprises in Hubei Province Is Not Good, and There Are Big Differences Among Industries}

From the perspective of financial situation, from 2016 to 2018, the short-term solvency of listed private enterprises in Hubei Province was better and improved year by year, and there was a big difference among industries, but the gap gradually narrowed in the three years; the long-term solvency of Hubei listed private enterprises was good but decreased year by year, and the financial leverage utilization ability showed a downward trend. It shows that Hubei listed private enterprises have strong short-term solvency, but there are some risks in long-term solvency. Although every industry in Hubei Province can basically maintain the normal circulation of enterprises, but the working capital is obviously insufficient and the operation capacity of enterprises is poor.
The profitability of listed private enterprises in Hubei Province fluctuated downward, and the profitability among industries also fluctuated significantly, indicating that the profitability of listed private enterprises in Hubei Province is insufficient. The development capacity of listed private enterprises in Hubei Province decreased year by year. Although a few enterprises have improved their development ability in the past three years, some industries even showed a sharp decline and the overall trend of decline showed that the development prospects of listed private enterprises in Hubei Province were worrying.

\subsection{Policy Recommendations}

\subsubsection{Enterprises Should Speed up the Upgrading and Transformation and Improve Their market Competitiveness}

Hubei listed private enterprises should first find their own position in the industry according to their own industries, find out their own advantages and disadvantages, so as to formulate the future development direction. Secondly, they should increase R \& D investment, improve the education level of employees, and strive to accelerate the transformation from labor-intensive industry to technology intensive industry, so as to improve their production efficiency. Thirdly, they should analyze their own financial situation in detail, find out the problems in the process of production and operation in time and make adjustments, while expanding the scale pay attention to the real improvement of the economic benefits of the enterprises, so as to improve the profitability, debt paying ability, operation ability and growth ability, improving the development prospect of the enterprise. Finally, efforts should be made to standardize the internal management, internal control and audit system, so as to enable enterprises to obtain broader development resources and platforms, so that the listed private enterprises in Hubei can really promote the overall economic development of Hubei more rapidly.

\subsubsection{Government Should Formulate Encouragement and Support Policies to Accelerate the Development of Listed Private Enterprises}

The development of private enterprises is closely related to the overall economic development of Hubei Province. Due to the limitation of their own scale and capital, they are in urgent need of a broader space for further development. Therefore, the government should formulate policies suitable for different private enterprises according to the characteristics of different enterprises and different industries and their current development situation, and relax the market access and reform requirements of developing mixed ownership economy, focus on formulating more relevant policies to attract and encourage outstanding private enterprises, establish fast track to simplify the administrative examination and approval procedures for entering the market, deepen financial reform, relieve the financing problems of private enterprises, and promote the function of industry associations and other organizations to serve enterprises, and 
constantly explore its role as a bridge and link between the government, enterprises and the market, really let the willing and capable private enterprises more easily enter the capital market, so as to truly achieve the original intention of promoting the better development of Hubei private enterprises.

\subsubsection{Government Should Continue to Improve the Tax System Reform, Optimize Tax Behavior, and Further Promote the Reduction of Tax Burden}

The original intention of replacing business tax with value-added tax is beneficial to private enterprises. However, due to the different nature and characteristics of private enterprises in different industries and sizes, there are obvious differences in tax reduction effect for different industries in practice. Therefore, the government should further implement the structural tax reduction reform of value-added tax according to the characteristics of private enterprises, formulating tax rates suitable for private enterprises, and Issue a positive list of corporate tax, alleviating the reality of the high tax burden of private enterprises, relaxing the restrictions on issuing VAT special invoices by small-scale taxpayers, further expand the scope of input tax deduction for private enterprises, and give private enterprises a certain period of tax exemption. In the process of economic development, local governments usually ignore the long-term effects because they only consider their own benefits during their tenure, which leads to the discontinuity of local government policies and damages the government's credit, which leads to the failure of the government's support policies for private enterprises. Therefore, the government should adhere to the continuity of preferential tax policies and put an end to the failure of tax recovery or preferential tax policies for private enterprises due to personnel changes of government departments, so as to really help promote the rapid development of listed private enterprises in Hubei.

\section{Project Supported}

Project of Management Science and Engineering of Key Disciplines in Hubei Province" An Empirical Study on the Development of Listed Private Enterprises in Hubei" (Project No. ZDXK2019YB08); Project of Manufacturing Industry Development Research Center on Wuhan City Circle" An Empirical Study on the Development of Listed Private Enterprises in Hubei-- Based on the Comparative Analysis of Manufacturing Industry and other Industries" (Project No. WZ2019Y04).

\section{References}

[1] Huiyi Zhang, Lei Du. Innovation driven, the role of government and the development of private economy-Threshold effect analysis based on data of 30 provinces and cities in China [J]. Journal of Henan Normal University (PHILOSOPHY AND SOCIAL SCIENCES EDITION). 2019 (7): 39-45.
[2] Jia Qi. Policy thinking of promoting high quality development of private enterprises in China-- Analysis on the effect of the support policies for Dengling Enterprises [J]. Learning and Practice.

[3] Junjie Sun, Fei Peng. An empirical test on the influence of financial development and R \& D investment on the financing ability of private enterprise $\mathrm{s}[\mathrm{J}]$. Statistics and decision making.

[4] Wujing Zheng. Five paths and opportunities for high quality development of private enterprises in the new era $[\mathrm{J}]$. JOURNAL OF GUANGXI UNIVERSITY FOR NATIONALITIES (PHILOSOPHY AND SOCIAL SCIENCES).

[5] Yue Wang, Chengyun Wang. Spatial temporal evolution and influencing factors of China's top 500 private enterprises [J]. Research on world geography.

[6] Gongxiang Hong, Qingqing Gu, Meisheng Dong. Theoretical and empirical research on the symbiotic development of state owned economy and private economy -- Based on the provincial panel data of China from 2000 to 2015 [J]. Political Economy Review.

[7] Qian Dong. Research on the influence of private enterprises on the development of urbanization in China-- Based on optimized vector autoregressive model $[\mathrm{J}]$. Economic management in East China. 2018 (11): 180-184.

[8] Han Yu, Zhonglun Yang, Zengji Song. Can state-owned equity bring benefits to private enterprises?-- An empirical study on Chinese Listed Companies [J]. Financial research. 2017 (4): 109-119.

[9] Haibing Wang, Huixin Yang. 40 years of reform and development of China's private economy: review and Prospect [J]. Economic and management research. 2018 (4): 3-14.

[10] Yunfei Bai, Yan Luan. Comparison of the contribution of human capital to economic growth between private enterprises and non private enterprises [J]. Statistics and decision making. 2019 (16): 181-184.

[11] Linxin Wang, Chuan Zuo. The symbiotic development relationship between state owned economy and private economy [J]. Fudan Journal (SOCIAL SCIENCE EDITION). 2019 (4): 159-168.

[12] Qianling Shen. Financial market competition, corporate governance and the growth of Chinese private enterprises: a cross level model $[\mathrm{J}]$. Journal of Yunnan University of Finance and Economics. 2018 (4): 56-69.

[13] John Kuada. Private Enterprise-Led Economic Development in Sub-Saharan Africa [M]. Palgrave Macmillan. 2015.

[14] James R. Barth, Dongyun Lin, Keven Yost. Small and Medium Enterprise Financing in Transition Economies [J]. Atlantic Economic Journal. 2011 (39): 19-38.

[15] Jun-Hwan Park, Bangrae Lee, Yeong-Ho Moon, Lee-Nam Kwon. Study for Selection of Industrial Areas Suitable to Small and Medium-Sized Enterprises (SMEs) in Korea [J]. Technology, Market and Complexity. 2016 (12): 2-19.

[16] Elaine Conway. Engaging Small and Medium-Sized Enterprises (SMEs) in the Low Carbon Agenda [J]. Energy, Sustainability and Society. 2015 (12): 5-32. 